\title{
Application of wall monitoring technique for backfill grouting in inclined concrete shaft
}

\author{
Feng Zhao ${ }^{1,2}$ Shuancheng $\mathrm{Gu}^{3}$ Shuning Dong ${ }^{4}$ \\ ${ }^{1}$ School of Construction Engineering, Xi'an University of Science and Technology,710054, xian, \\ shanxi, China \\ ${ }^{2}$ Xi'an Research Institute,China Coal Technology and Engineering Group Corp, 710054, xian, \\ shanxi, China \\ ${ }^{3}$ School of Construction Engineering, Xi'an University of Science and Technology,710054, xian, \\ shanxi, China \\ ${ }^{4}$ Xi'an Research Institute,China Coal Technology and Engineering Group Corp, 710054, xian, \\ shanxi, China
}

\begin{abstract}
KEYWORDS: wall monitoring technique, backfill grouting, inclined concrete shaft
ABSTRACT: Grouting water plugging after main inclined shaft of Dafosi coal mine engineering instance, to ensure the safety of the shaft wall in the process of grouting, for the purpose of borehole wall monitoring scheme is proposed. Using strain monitoring technique, the wellbore hydrological and engineering geological conditions of surrounding rock in different location arrangement of monitoring stations, through the analysis of the monitoring instrument in the process of grouting wall stress change and the status of the casing deformation, and real-time monitoring and adjusting the grouting pressure, through the data analysis of shaft wall deformation law mastered the grouting process, grouting engineering provides the accurate monitoring data security and safety technology, therefore, study the application of monitoring technology in the wall after grouting has a very positive role.
\end{abstract}

\section{INTRODUCTION}

As a new field of engineering technology, grouting technology has more than one hundred years history (Weng(2014) \&Zhang(2011) \&Wang(2004)). Its theoretical research and development is very rapid, but especially under the condition of dynamic water wall post grouting technique for slope (tunnel, tunnel and other concrete structures) wall after grouting water plugging, governance, the damage is not yet mature, the application of research of monitoring technology in the backfill grouting is not much, so the monitoring technology in the application of backfill grouting, the study has a very positive role and can provide certain reference for design and construction (Xie(2004) \&Qian(2013) \&Yang(2011) \&Wang(2006)).

Dafosi mine is in the southern of Binchang mining. Area $86.3 \mathrm{~km}^{2}$, Geological reserves 1249.92Mt, Recoverable reserves $765.68 \mathrm{Mt}$. Production capacity is $6.00 \mathrm{Mt} / \mathrm{a}, 92.5 \mathrm{a}$ service. The main shaft angle is 14 degrees, plagioclase $916 \mathrm{~m}$; vice inclined shaft angle of 20 degrees, length $647 \mathrm{~m}$. The main and auxiliary inclined wellbore both appear serious gushing phenomena in crossing the aquifer, while the shaft has arching concrete into the mine, but shaft backfill gushing still in large area through the reserved hole pipe, construction joint, crack. After analyzing the reason of gushing, backfill grouting method is used to block gushing channel behind wellbore wall, then adopt the method of shallow hole grouting to fill the void behind the wall and low pressure intermittent filling grouting construction technology to achieve the effect of plugging.

Slope through the formation of the geologic conditions are complex. In the process of grouting, monitor the strain of wellbore in order to prevent the damage caused by large pressure. Choose the wellbore hydrological and engineering geological conditions of surrounding rock in different location to arrange monitoring stations. By monitoring the strain condition in grouting, can provides the basis for other similar conditions of reasonable pressure control in backfill grouting. 


\section{Principle of borehole wall monitoring technology}

\section{The principle and processing method for calculation of stress}

The calculation formula of the concrete stress $\sigma_{\mathrm{c}}$ for:

$\sigma_{c}=\mathrm{E}_{c} \varepsilon_{c}$

where $\varepsilon_{\mathrm{c}}=\Phi(f)$ function, by the strain gauge calibration data are given, $\mu \varepsilon ; \mathrm{E}_{\mathrm{c}}=$ Embedding of the strain gauge concrete elastic modulus, GPa .

Because $\varepsilon_{\mathrm{c}}$ is $\Phi(\mathrm{f})$ function and the zero stress at the time of the initial frequency of f0 two parties, therefore the determine of initial frequency $f_{0}$ is very important for the accuracy of calculation of concrete stress.

\section{Strain measuring instrument}

Using GHB-3 steel string concrete strain gauge produced by Dandongsanda testing instrument factory, its main technical indicators shown in table 1 .

Table 1. Steel string strain gage technique parameters.

\begin{tabular}{cc}
\hline Related & value \\
parameters & GHB-3 type steel string \\
strain gage \\
Dodel No. & oscillation \\
Oxcontinuous \\
Working mode & $30 \Omega$ \\
Coil resistance & $0.7 \mu \varepsilon / \mathrm{Hz}$ \\
Resolution & $<1.0 \% \mathrm{~F} \cdot \mathrm{S}$ \\
Don't repeat rate & $<1.0 \% \mathrm{~F} \cdot \mathrm{S}$ \\
Return & $<1.5 \% \mathrm{~F} \cdot \mathrm{S}$ \\
difference & $1.0 \% \mathrm{~F} \cdot \mathrm{S}$ \\
Comprehensive & $-30 \sim 70{ }^{\circ} \mathrm{C}$ \\
error & $150 \mathrm{~mm}$ \\
Long term & $0.5 \mathrm{Kg}$ \\
stability & \\
Working & \\
temperature & \\
Length & Weight
\end{tabular}

Strain gauges are buried in concrete brickwork by gouging in depth of $200 \mathrm{~mm}$, filling and compacting with concrete lining wall with the strength of cement mortar, the data line keep outside the hole, then start backfill grouting monitoring when the concrete reach 7 days strength.

\section{The working principle of concrete strain gauge}

The steel slight oscillation in strain sensors, the relationship of its natural frequency of vibration $\mathrm{f}$ and axial stress $\sigma$ as follows:

$f=\frac{2}{2 L} \sqrt{\frac{\sigma}{\rho}}$

where $\mathrm{L}=$ steel effective length, $\mathrm{mm} ; \rho=$ steel volume density, $\mathrm{Kg} / \mathrm{m}^{3} ; \sigma=$ axial stress, MPa.

\section{Monitoring method}

\section{Monitoring points arrangement}

Main incline shaft were selected in the inclined length $201 \mathrm{~m}, 252 \mathrm{~m}, 319 \mathrm{~m}$, a total of three monitoring sections, each monitoring section has three monitoring stations, respectively located in the roof and two side of the wall. As shown in figure 1. 


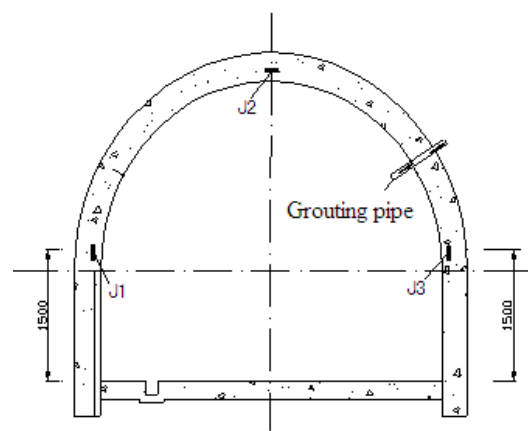

The profile of Monitoring Section in the inclined length of $319 \mathrm{~m}$

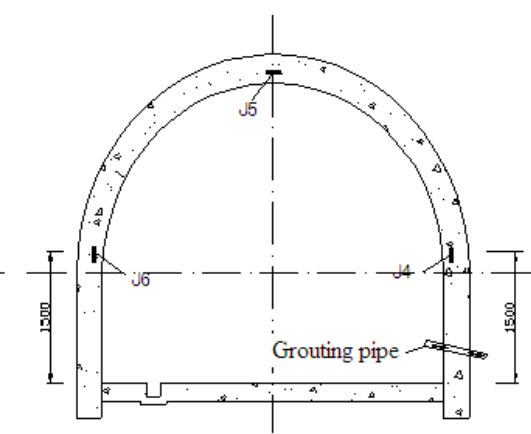

The profile of Monitoring Section in the inclined length of $252 \mathrm{~m}$

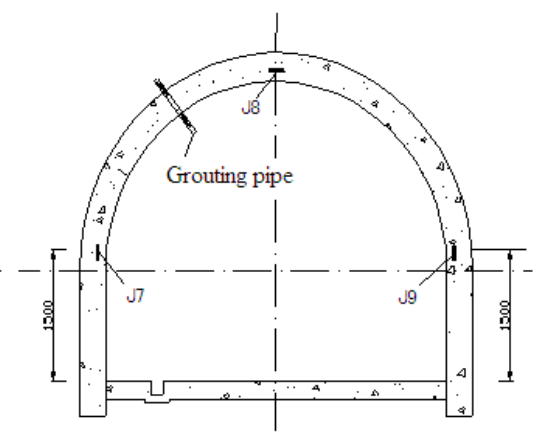

The profile of Monitoring Section in the inclined length of $201 \mathrm{~m}$

Figure 1 Main slope monitoring profile

\section{The strain data acquisition}

By the research of sensor technology Dandongsanda produced GPC-6 multichannel steel string frequency readout instrument, its main technical indicators shown in table 1.

Data collection was conducted in the vicinity of grouting working face, through the instrument readings will strain gauge change display and saving.

Table 2. Data acquisition instrument technology parameter table

\begin{tabular}{|c|c|}
\hline $\begin{array}{l}\text { Technical } \\
\text { parameters }\end{array}$ & value \\
\hline $\begin{array}{l}\text { The use of } \\
\text { temperature }\end{array}$ & $0 \sim 50^{\circ} \mathrm{C}$ \\
\hline Input channel & $1 \sim 6$ \\
\hline Sampling period & 0.8 seconds / Channel \\
\hline Data storage & $\begin{array}{l}\text { The } 2000 \text { frequency } \\
\text { number }\end{array}$ \\
\hline The scope of work & $800 \sim 3000 \mathrm{~Hz}$ \\
\hline $\begin{array}{l}\text { Frequency } \\
\text { measurement } \\
\text { resolution }\end{array}$ & $0.1 \mathrm{~Hz}$ \\
\hline $\begin{array}{l}\text { The modulus of } \\
\text { resolution }\end{array}$ & $\begin{array}{l}\text { 0.1F; F- } \\
\text { Modulus.Modulus = } \\
\text { frequency value of the } \\
\text { square } / 1000\end{array}$ \\
\hline Display mode & $\begin{array}{l}\text { Frequency, modulus } \\
\text { five digit display }\end{array}$ \\
\hline $\begin{array}{l}\text { Rechargeable } \\
\text { batteries }\end{array}$ & $\begin{array}{l}\text { Continuous work full of } \\
\text { electricity for } 8 \text { hours }\end{array}$ \\
\hline Volume & $260 \times 160 \times 135 \mathrm{~mm}$ \\
\hline Weight & $2.8 \mathrm{~kg}$ \\
\hline
\end{tabular}

\section{Casing deformation monitoring}

\section{Grouting Monitoring}

Monitoring of borehole strain in the grouting process, every 2 minutes of observation and record at a time of grouting location, process and climate conditions have also made the corresponding record, and test the safety of grouting pressure based on monitoring data.

In the grouting process, by analyzing the monitoring data of borehole stress and changes of sidewall safety condition to provides accurate monitoring data for the entire grouting engineering, so the grouting station can make timely adjustment of grouting pressure.

\section{Monitoring results}

The monitoring data of the inclined length $319 \mathrm{~m}$ is shown in Figure 2. 


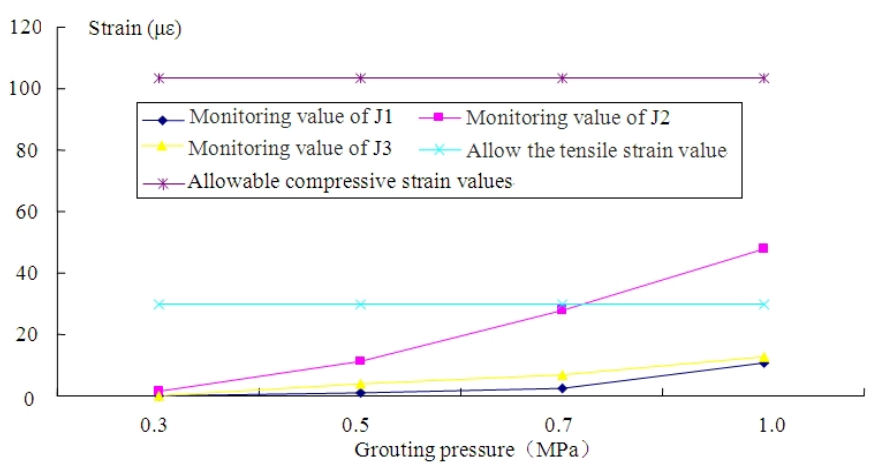

Figure 2 The monitoring curve of the relationship between the grouting pressure and strain in the inclined length of $319 \mathrm{~m}$

J1 point of tension, $\Delta \varepsilon \max =10.933 \mu \varepsilon<$ permissible value calculation $30 \mu \varepsilon$, with the grouting pressure and the increasing duration, the value of tensile deformation is also increase but not close to the permissible value.

J2 point of pressure, $\Delta \varepsilon \max =47.890 \mu \varepsilon<$ permissible value calculation $103.3 \mu \varepsilon$, with the grouting pressure and the increasing duration, the value of compressive deformation is also increase but not close to the permissible value.

J3 point of tension, $\Delta \varepsilon \max =12.703 \mu \varepsilon<$ permissible value calculation $30 \mu \varepsilon$, with the grouting pressure and the increasing duration, the value of tensile deformation is also increase but not close to the permissible value.

The monitoring data of the inclined length $252 \mathrm{~m}$ is shown in Figure 3.

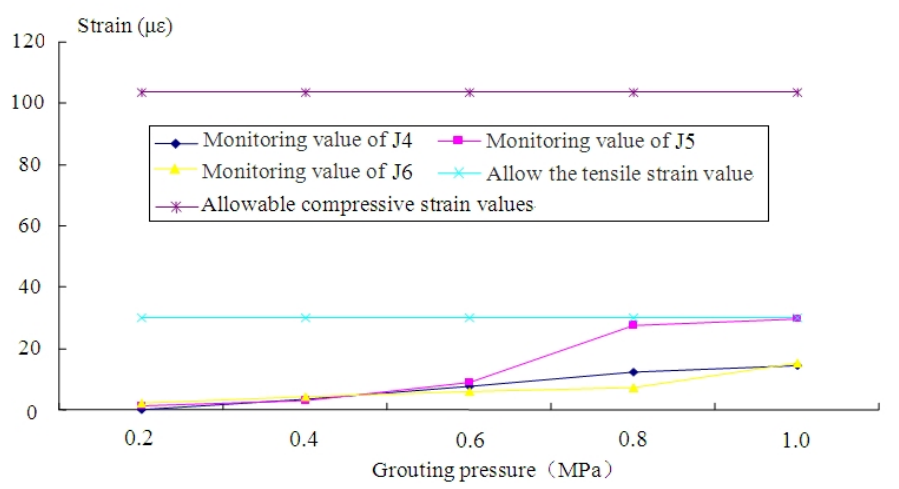

Figure 3 The monitoring curve of the relationship between the grouting pressure and strain in the inclined length of $252 \mathrm{~m}$

J4 point of tension, $\Delta \varepsilon \max =14.384 \mu \varepsilon<$ permissible value calculation $30 \mu \varepsilon$, with the grouting pressure and the increasing duration, the value of tensile deformation is also increase but not close to the permissible value.

J5 point of pressure, $\Delta \varepsilon \max =29.437 \mu \varepsilon<$ permissible value calculation $103.3 \mu \varepsilon$, with the grouting pressure and the increasing duration, the value of compressive deformation is also increase but not close to the permissible value.

J6 point of tension, $\Delta \varepsilon \max =15.035 \mu \varepsilon<$ permissible value calculation $30 \mu \varepsilon$, with the grouting pressure and the increasing duration, the value of tensile deformation is also increase but not close to the permissible value.

The monitoring data of the inclined length $201 \mathrm{~m}$ is shown in Figure 4. 


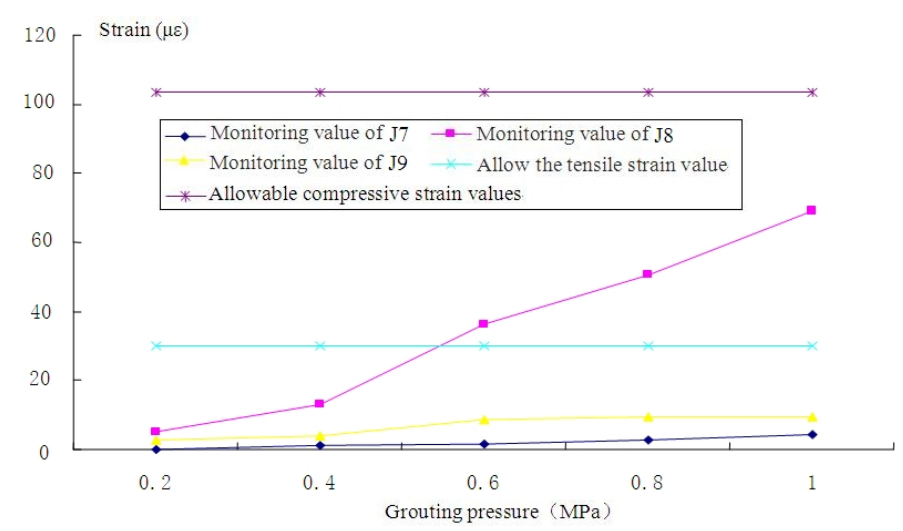

Figure 4 The monitoring curve of the relationship between the grouting pressure and strain in the inclined length of $201 \mathrm{~m}$

J7 point of tension, $\Delta \varepsilon \max =4.211 \mu \varepsilon<$ permissible value calculation $30 \mu \varepsilon$, with the grouting pressure and the increasing duration, the value of tensile deformation is also increase but not close to the permissible value.

J8 point of pressure, $\Delta \varepsilon \max =69.192 \mu \varepsilon<$ permissible value calculation $103.3 \mu \varepsilon$, with the grouting pressure and the increasing duration, the value of compressive deformation is also increase but not close to the permissible value.

J9 point of tension, $\Delta \varepsilon \max =9.614 \mu \varepsilon<$ permissible value calculation $30 \mu \varepsilon$, with the grouting pressure and the increasing duration, the value of tensile deformation is also increase but not close to the permissible value.

\section{Grouting monitoring conclusion}

(1)The grouting pressure is safety, the shaft deformation is generally small, the shaft without damage. The maximum compressive strain value is $69.192 \mu \varepsilon$, the pressure less than the allowable strain value $103.3 \mu \varepsilon$; the maximum tensile strain is $15.035 \mu \varepsilon$, less than the allowable tensile strain $30 \mu \varepsilon$. The allowable compressive strain value according to the concrete designed with stand pressure calculation, $\varepsilon=\sigma / \mathrm{E}$, the wall' Concrete design pressure is $3.1 \mathrm{MPa}$, the elastic model of concrete is $30 \mathrm{GPa}$ 。

(2)The monitoring sites structure of the wall concrete is not damage before the grouting;

(3)The strain gage performance is good after been embedded.

\section{Analysis of shaft wall deformation}

According to the monitoring of the shaft wall strain data and the engineering situation can be draw: with the grouting pressure and the increasing duration.

(1)The vault have the trend of movement to the middle, this because the part of vault produced the cavity when brickwork, grouting slurry concentration effect makes vault had a trend to move towards the centre;

(2)The side of the rock way has the movement trend to the surrounding rock, this because that the sides has been more dense after brickwork, so when is grouting, the sides under the arch of wellbore effect has the movement to the surrounding rock;

(3)Although the floor has not been monitored, but in the course of construction when grouting pressure reaches $1.5 \mathrm{MPa}$ the floor has drum phenomenon, this because that the thickness of floor has only $200 \mathrm{~mm}$ when brickwork, when the pressure is too high, the deformation will be larger even occur rapture.

\section{Conclusions}

(1)Backfill grouting has certain influence for the deformation of the retaining structure, but the deformation is small, with increasing of the grouting pressure, the roof and floor move in the middle 
of the wellbore, on the contrary, both sides of the wall bulge outward.The success of the wall deformation monitoring can be a reference in the future.

(2)Wall after grouting pressure is generally calculated by theory, but also should be adjusted by combining real-time deformation monitoring data to ensure the shaft safety.

(3)With the development of information technology, the use of advanced wireless communications and digital visual technology to realize the ground $3 \mathrm{~d}$ video wall deformation monitoring is the research direction in the future.

\section{REFERENCES}

[1] Weng Mingyue.2014. Application of backfill grouting technology with deep borehole to liner of mine shaft.Coal Engineering 5(46):33-35.

[2] Zhang Pingsong \& Guo Liquan.2011. Detection technology by reflection wave for backwall grouting quality of a vertical shaft. Journal of Mining and Safety Engineering 1(28):115-121.

[3] Wang Weicheng.2004. Monitoring and analysis of shaft deformation of the Haizi coal.mine $4(6): 42-43$.

[4] Xie Wenhua,Chen Yuhua,Lu Shiliang.2004. Analyzing the relation about the Soft rock chamber'surrounding rock. Journal of Hunan University of Science and Technology 2(19):6-9.

[5] Qian Ziwei,et al.2013. Research on backfill grouting based on surrounding rock loose circle theory. Journal of China Coal Society 2(38):189-193.

[6] Yang Zhijiang1,et al.2011. In-situ measurement and analysis of drilling shaft lining concrete strain during sinking. Journal of China Coal Society 9(36):1463-1468.

[7] Wang Yansen,et al.2006. Study of freeze sinking period concrete strain of outer shaft wall of Longgu Coa1Mine auxiliary shaft. Journal of China Coal Society 3(31):296-300. 